\title{
As mediações no desenvolvimento de um tratamento para a Covid-19: pescando actantes
}

\section{Mediation in the development of a treatment for COVID-19: fishing for actants}

\section{Las mediaciones en el desarrollo de un tratamiento para COVID-19: pescando actantes}

\author{
iD (9) Bruno Rossi Lorenzi \\ Universidade Federal de São Carlos, São Carlos, São Paulo, Brasil \\ brunolorenzi@gmail.com \\ iD Tarcísio de Sá Cardoso \\ Universidade Federal da Bahia, Salvador, Bahia, Brasil \\ tcardoso@ufba.br \\ iD Julio Cesar Cetrulo Lorenzi \\ The Rockefeller University, Nova York, Estados Unidos \\ jcetrulolo@rockefeller.edu
}

Resumo: Este artigo tem como objetivo analisar sociologicamente as ações da ciência em busca de tratamento para a COVID-19. Para tal, este trabalho contou tanto com conhecimentos e relatos de campo elaborados por um cientista envolvido diretamente na pesquisa de um tratamento, quanto com uma análise das mediações a partir da sociologia das associações, prisma teórico proposto pelo sociólogo, antropólogo e filósofo Bruno Latour. Os esforços realizados pela ciência para buscar tratamentos para o novo coronavírus foram tomados, no presente texto, a partir de um caso específico: o trabalho de pesquisa que está sendo desenvolvido pelo Laboratório de Imunologia Molecular (MIL) da Universidade Rockefeller. A partir da descrição do caso, fomos capazes de relacionar a ação dos cientistas com os conceitos de Bruno Latour, 
como a mediação que envolve os artifícios utilizados para identificar, capturar e replicar as células B específicas que são capazes de combater o vírus, a ação dos não humanos necessários para isso, como o uso de uma isca proteica para "pescar" as células B, e o encadeamento desses elementos em forma de rede [RES] necessário para o desenvolvimento do tratamento. Com isso, esperamos demonstrar não só como a literatura latouriana se manteve atual na descrição do trabalho da ciência, fornecendo ferramentas que nos ajudam a entender a dinâmica híbrida dessa atividade, mas também, como a continuidade de nossa permanência depende da articulação ou mediação criativa das descontinuidades e actantes que nos cercam.

Palavras-chave: SARS-CoV-2. Covid-19. Actante. Latour. Tratamento.

Abstract: This article aims to analyze sociologically the actions of science in search of treatment for COVID-19. To this end, this work relied both on knowledge and field reports prepared by a scientist directly involved in the research of a treatment, and on an analysis of mediations from the sociology of associations, a theoretical prism proposed by the sociologist, anthropologist and philosopher Bruno Latour. The efforts made by science to seek treatments for the new coronavirus were taken, in this text, from a specific case: the research work being developed by the Molecular Immunology Laboratory (MIL) of Rockefeller University. From the description of the case, we were able to relate the scientists' action with Bruno Latour's concepts, such as the mediation that involves the artifices used to identify, capture and replicate the specific B cells that are capable of fighting the virus, the action of the non-humans needed for this, such as the use of a protein bait to "fish" the B cells, and the networking of these elements [RES] necessary for the development of the treatment. Thus we demonstrated not only how the Latourian literature has remained current in describing scientific work, providing tools that help us understand the heterogeneous dynamics of this activity, but also how the continuity of our permanence depends on the creative articulation or mediation of the discontinuities and actors that surround us.

Keywords: SARS-CoV-2. COVID-19. Actant. Latour. Treatment. 
Resumen: Este artículo tiene como objetivo analizar sociológicamente las acciones de la ciencia en busca de tratamiento para COVID-19. Para ello, este trabajo se basó tanto en conocimientos como en informes de campo elaborados por un científico directamente involucrado en la investigación de un tratamiento, así como en un análisis de mediaciones desde la sociología de las asociaciones, prisma teórico propuesto por el sociólogo, antropólogo y filósofo Bruno Latour. Los esfuerzos realizados por la ciencia para buscar tratamientos para el nuevo coronavirus fueron tomados, en este texto, de un caso específico: el trabajo de investigación que está desarrollando el Laboratorio de Inmunología Molecular (MIL) de la Universidad Rockefeller. A partir de la descripción del caso, pudimos relacionar la acción de los científicos con los conceptos de Bruno Latour, como la mediación que involucra los dispositivos utilizados para identificar, capturar y replicar células B específicas que son capaces de combatir el virus, la acción de los no humanos necesarios para esto, como el uso de cebo proteico para "pescar" células $B$, y el encadenamiento de estos elementos en forma de una red [RES] necesaria para el desarrollo del tratamiento. Con esto, esperamos demostrar no solo cómo la literatura latouriana se ha mantenido vigente en la descripción de la trabajo científico, aportando herramientas que nos ayuden a comprender la dinámica heterogénea de esta actividad, sino también cómo la continuidad de nuestra permanencia depende de la articulación o mediación creativa de discontinuidades y actantes que nos rodean.

Palabras clave: SARS-CoV-2. COVID-19. Actante. Latour. Tratamiento.

Data de recebimento: 29/09/2020

Data de aprovação: 11/02/2021 
As mediações no desenvolvimento de um tratamento para a Covid-19: pescando actantes Bruno Rossi Lorenzi • Tarcísio de Sá Cardoso • Julio Cesar Cetrulo Lorenzi

\section{Introdução}

O presente artigo tem como objetivo analisar, sociológica e epistemologicamente, as ações da ciência em busca de tratamento para o SARS-CoV-2. Para tal, este trabalho conta tanto com conhecimentos e relatos de campo elaborados por um cientista pesquisador quanto com uma análise das mediações a partir da sociologia das associações, prisma teórico proposto pelo sociólogo, antropólogo e filósofo Bruno Latour. Os esforços realizados pela ciência para buscar tratamentos para o novo coronavírus serão tomados, no presente texto, a partir de um caso específico: o trabalho de pesquisa que está sendo desenvolvido pelo Laboratório de Imunologia Molecular (MIL'1) da Universidade Rockefeller, nos Estados Unidos, no mesmo momento em que este artigo é escrito, e conta com a contribuição direta de um dos membros do laboratório envolvido na pesquisa, membro este que também é um dos autores do presente artigo. A partir do relato do pesquisador e da visualização dos esforços empreendidos pela equipe científica envolvida, busca-se tomar tal equipe como uma rede [NET], no sentido colocado por Latour, no intuito de apontar e compreender, através dessa ótica, a rede de actantes envolvidos e os processos de mediação que pretende chegar a um efeito específico na rede do social: a disponibilização do tratamento para o SARS-CoV-2. O artigo está dividido em quatro partes: (I) apresentação sintética do coronavírus e do SARS-CoV-2; (II) apresentação sobre as buscas da ciência e sobre o caso da pesquisa no laboratório MIL; (III) apresentação sintética das ideias de Bruno Latour (especialmente, as ideias de rede actante, mediação e não humano); e (IV) análise latouriana da ciência em ação na busca por tratamento para a Covid-19.

1 Laboratory of Molecular Immunology. Disponível em: https://www.niaid.nih.gov/research/lab-molecular-immunology. Acesso em: 02 fev. 2021. 


\section{Coronavírus, SARS-CoV-2 e busca por tratamentos}

O vírus causador da síndrome respiratória severa (do inglês Severe acute respiratory syndrome coronavirus 2 ou SARS-CoV-2) foi primeiramente identificado no final de 2019 na China (ZHOU et al., 2020). Esse vírus é o causador da Covid-19 (do inglês coronavirus disease 2019) ((WHO2). Os coronavírus são vírus que possuem uma fita simples de RNA que codifica suas informações genéticas. Eles são vírus que possuem um envelope, com uma proteína espícula em sua superfície, necessária para a interação com os receptores encontrados nas células-alvo durante a infecção (Lu et al., 2020).

De maneira simplificada, podemos dividir a infeção por SARSCoV-2 em duas fases. A primeira tem início quando o indivíduo entra em contato com o vírus, seja por via aérea, seja por contato físico. Uma vez que ocorre a infecção, o vírus começa a proliferar na cavidade nasal onde permanece por vários dias (LU et al., 2020). Nessa fase, geralmente o indivíduo contaminado tem poucos sintomas visíveis, como perda de olfato e paladar, e começa a ser ele próprio um espalhador da doença. Em seguida, o vírus prolifera no sistema respiratório superior (boca, nariz, traqueia) e migra para os pulmões. Ocorrem novos sintomas como febre, tosse, dor de garganta, podendo culminar em um comprometimento dos pulmões. Essa primeira fase dura, geralmente, uma semana e se parece muito com uma gripe comum e na maioria dos casos o sistema imune inato consegue controlar a infecção e o paciente tem melhora completa (KARAGIANNIDIS et al., 2020).

No entanto, em torno de $5 \%$ dos casos a doença progride para a segunda fase. Nesse período, que começa entre 7 e 14 dias após a infecção original, ocorre uma mudança drástica no causador dos sintomas. Nesses casos, a proliferação viral não é controlada e o sistema imune responde de maneira severa a essa infecção. Nessa etapa os pacientes começam a desenvolver sintomas semelhantes a algumas doenças autoimunes, em que as células do sistema imunológico produzem moléculas capazes de atacar a infecção, 
As mediações no desenvolvimento de um tratamento para a Covid-19: pescando actantes Bruno Rossi Lorenzi • Tarcísio de Sá Cardoso • Julio Cesar Cetrulo Lorenzi

mas que podem ter diversos efeitos colaterais. Já é bem documentada essa etapa quando a infeção original no pulmão leva à chamada tempestade de citocinas, que têm efeitos globais no corpo humano, como comprometimento do sistema circulatório, principalmente dos fatores de coagulação, e potencial perda da capacidade pulmonar, fazendo com que os pacientes tenham que ser tratados com ventilação mecânica. Pacientes que chegam a tal nível de comprometimento têm uma chance reduzida de sobrevivência e a taxa de óbitos nos pacientes levados ao respirador pode chegar a 60\% (KARAGIANNIDIS et al., 2020).

As origens do SARS-CoV-2 ainda não são completamente conhecidas e não são objeto do presente estudo. A hipótese sustentada por Andersen et al. propôs uma origem baseada na transferência de um coronavírus que originalmente infectou morcegos e que, em seguida, passou a infectar humanos (Andersen et al., 2020), porém muitas questões ainda precisam ser respondidas e para isso a Organização Mundial da Saúde (OMS) está empreendendo uma investigação detalhada dos primeiros casos ocorridos na China, em torno dos eventos iniciadores da pandemia (MALLAPATY, 2020, RASMUSSEM, 2021).

Uma característica importante dos coronavírus é sua alta taxa mutacional. Sabemos que os coronavírus podem evoluir, isto é, mudar a composição de seu genoma rapidamente (KORBER et al., 2020). Essas mutações são aleatórias e podem trazer novidades, como, por exemplo, a capacidade de infectar novas células ou tornar o vírus inativo. No caso do SARS-CoV-2, sabemos exatamente quais inovações genéticas ocorreram para que esse vírus passasse a infectar células humanas com alta eficiência (BONI et al., 2020). Para o desenvolvimento do que se segue, no entanto, é importante lembrar que a hipótese mais aceita para a origem do SARS-Cov-2 está relacionada com os clássicos movimentos dos vírus entre diferentes espécies. Diferentes coronavírus são reconhecidamente capazes de infectar morcegos, camelos, porcos e diversas aves (CUI; LI; SHI, 2019). Dessa forma, o vírus é capaz de infectar diferentes células em diferentes espécies, fato que só é 
As mediações no desenvolvimento de um tratamento para a Covid-19: pescando actantes Bruno Rossi Lorenzi • Tarcísio de Sá Cardoso • Julio Cesar Cetrulo Lorenzi

possível uma vez que esses vírus têm uma grande variabilidade genética e, além disso, podem trocar pedaços de seu genoma com o de outro coronavírus, em um possível encontro em um hospedeiro comum. Classicamente, essa troca é chamada de recombinação de genomas (fenômeno que ocorre quando dois vírus infectam a mesma célula e recombinam seu genoma).

O desenvolvimento de vacinas para a Covid-19 é um marco na ciência mundial. A resposta dos cientistas e indústria farmacêutica foi muito rápida, possibilitando a aprovação do uso de novas vacinas ainda em 2020. Desde a detecção dos primeiros casos e obtenção da sequência do genoma do SARS-CoV-2, ainda em fevereiro de 2020 (ZHOU et al., 2020), percebeu-se que uma vacina seria necessária. Na corrida científica em busca da vacina, muitas possibilidades foram testadas. Diversas estratégias vacinais como o uso de vírus inativados, vírus atenuados, proteínas virais e até mesmo ácidos nucleicos que codificam para proteínas virais foram testados em modelos animais e posteriormente em humanos. Esse esforço coletivo das diversas equipes de cientistas em busca da vacina para o SARS-CoV-2 é um importante marco histórico para a humanidade, visto que geralmente novas vacinas demoram até 10 anos para ficarem prontas.

Essa velocidade é socialmente importante, pois, não apenas expressa a batalha contra o avanço da pandemia, já que o ritmo de novas infecções da Covid-19 foi crescendo em curvas inversamente proporcionais ao isolamento social de cada sociedade, mas, além disso, é um feito socialmente relevante, pois evidencia o que Latour tem chamado em textos recentes (LATOUR, 2020a, LATOUR, 2020b) de "plasticidade da ordem mundial". Ou seja, as dinâmicas sociais e econômicas que a narrativa moderna e modernizante diziam ser impossíveis de serem freadas puderam, enfim, ser suspensas em prol da emergência de um reagenciamento de forças sociais.

Uma parte da ação da ciência com relação à equação entre coronavírus e as questões sanitárias diz respeito à busca por vacinas, um tipo de terapia imune ativa, em que o próprio indivíduo seria 
As mediações no desenvolvimento de um tratamento para a Covid-19: pescando actantes Bruno Rossi Lorenzi • Tarcísio de Sá Cardoso • Julio Cesar Cetrulo Lorenzi

capaz de produzir seus anticorpos sem necessidade de transferência ou infecção. A vacinação, vale ressaltar, é um processo no qual os indivíduos recebem o agente agressor, ou pedaços do mesmo, com o intuito de gerar uma resposta das células $B$ (células que produzem os anticorpos). A vacina pode ser composta de diversos tipos de agentes, porém, em todos os casos, os organismos são inativados para maior segurança da vacina. Existem muitos exemplos de vacinas eficazes, como as de sarampo, rubéola, paralisia infantil e, mais modernamente, contra a gripe etc. Em todos esses exemplos, a vacina é composta por vírus inativados ou proteínas virais que são processadas pelo sistema imune, culminando na seleção de células B específicas e na produção de anticorpos. Uma característica desse tipo de imunização é a geração de células $B$ de memória que persistem por diversos anos no corpo do indivíduo vacinado e são capazes de serem ativadas quando encontrarem aquele mesmo agressor no futuro.

Por mais que diversas vacinas para a Covid-19 tenham sido desenvolvidas em tempo recorde e muitas já estejam disponíveis em vários países, o problema de sua produção em escala mundial ainda persistirá por algum tempo, sendo que o número de doses fabricadas ainda é muito inferior ao necessário para imunizar todas as pessoas no mundo e no Brasil. Esse fato ressalta a importância do desenvolvimento de tratamentos para a Covid-19, como o explorado nesse artigo, posto que milhões de pessoas ainda poderão ser infectadas e adoecer antes de serem vacinadas (MULLARD, 2020).

Além das vacinas, outra parte das ações coletivas da ciência é a busca por fontes alternativas de anticorpos para o tratamento da Covid-19. O presente estudo vai se concentrar em um tipo de tratamento que é baseado no uso e entendimento das células $B$, presentes no sangue de pacientes curados da doença. Esses pacientes passaram por todas as fases descritas anteriormente reconhecimento, ativação e produção de anticorpos pelas células B - e seu sangue está repleto desses anticorpos protetores. Desse modo, diversos hospitais pelo mundo estiveram testando o uso 
As mediações no desenvolvimento de um tratamento para a Covid-19: pescando actantes Bruno Rossi Lorenzi • Tarcísio de Sá Cardoso • Julio Cesar Cetrulo Lorenzi

do plasma sanguíneo obtido desses doadores para o tratamento de pacientes que estavam doentes. É esse tipo de tratamento que iremos abordar em nossa análise, isto é, uma forma de terapia passiva (em contraste com a vacina, que seria uma terapia ativa), já que depende de repetidas doses para sua eficiência.

\section{O caso de uma busca por tratamento para Covid-19 do MIL}

A pesquisa científica da Covid-19 pode ser comparada a um tsunami de informações. Essa verdadeira corrida pelo conhecimento se iniciou em janeiro de 2020 com os primeiros casos de infecção por SARS-CoV-2 na China. A princípio, ninguém imaginava que essa nova doença iria se espalhar por todo o mundo, porém, diversos laboratórios começaram a se preparar para essa possibilidade. O evento mais importante nesse estágio foi a disponibilização do genoma do vírus por cientistas chineses (ZHOU et al., 2020). A importância dessa ação se reflete, principalmente, em duas áreas da luta contra a doença.

A primeira é o diagnóstico, uma vez que, com a disponibilidade do genoma do SARS-CoV-2, cientistas foram capazes de rapidamente desenvolver ensaios para a detecção viral em humanos. Ainda hoje, o principal teste para a deteç̧ão da infecção é realizado pelo uso da técnica de RT-PCR, utilizando reagentes que reconhecem partes do vírus, mas que só puderam ser desenvolvidos por conta do conhecimento da sequência do genoma viral. A segunda área impactada pela disponibilidade do genoma foi a pesquisa para o desenvolvimento de tratamentos e vacinas. Uma variável importante nesse tipo de pesquisa é o isolamento de células $B$ específicas para o vírus. Neste texto, iremos focar nas pesquisas que buscam esses anticorpos.

Em busca de melhor entender e possivelmente tratar a Covid-19, diversos pesquisadores estiveram estudando as características da resposta imune na doença. Os principais estudos nesta 
As mediações no desenvolvimento de um tratamento para a Covid-19: pescando actantes Bruno Rossi Lorenzi • Tarcísio de Sá Cardoso • Julio Cesar Cetrulo Lorenzi

área focalizaram na resposta imune adaptativa, buscando entender como o corpo humano respondia à infecção viral (LEDFORD, 2020; LIU et al., 2020; ROBBIANI et al., 2020; ZOST et al., 2020). A resposta imune adaptativa pode ser descrita como um conjunto de células e tecidos componentes do sistema imune que tem como função principal produzir anticorpos que neutralizam a infecção. Nesse processo, as células B são essenciais, uma vez que elas podem identificar o organismo agressor diretamente por seu receptor de antígenos (essas células são as únicas capazes de produzir anticorpos e nosso corpo tem milhões dessas células). Esse conjunto de células $B$ tem uma característica única, cada uma delas é capaz de reconhecer um pedaço específico de proteína (mais conhecido como antígeno). Cada célula B já "nasce" predestinada a reconhecer apenas um único tipo de antígeno e essa especificidade é codificada no genoma dessa célula. A existência desse conjunto de células $B$ faz com que o sistema imune possa reconhecer os mais variados agressores e, potencialmente, responder rapidamente ao mesmo.

A resposta imune adaptativa se inicia quando a célula $B$ encontra seu antígeno por meio de seu receptor. Após esse encontro, a célula B é ativada e inicia uma transformação quando seu receptor, específico para aquele organismo agressor, passa a ser produzido na forma de anticorpos, que mantém a especificidade contra o organismo agressor e é capaz de neutralizá-lo. No caso das infecções virais, essa neutralização ocorre quando o anticorpo reconhece a parte do vírus que é necessária para a infecção de uma célula humana, impossibilitando a infecção da mesma. Cada célula $B$ ativada é capaz de produzir milhões de cópias desse anticorpo que será diluído no sangue e será capaz de encontrar o organismo agressor e neutralizá-lo.

As pesquisas referentes ao tratamento desenvolvidas pelo MIL ${ }^{2}$ buscaram identificar e capturar as células B em indivíduos que responderam bem à doença para produzir in vitro os anticorpos gerados por essas células e utilizá-los no tratamento de pacientes

20 relato deste caso de pesquisa e desenvolvimento, descrito nesta seção do texto, é narrado justamente pelo coautor do artigo, membro pesquisador do MIL e participante direto desta pesquisa. 
As mediações no desenvolvimento de um tratamento para a Covid-19: pescando actantes Bruno Rossi Lorenzi • Tarcísio de Sá Cardoso • Julio Cesar Cetrulo Lorenzi

nas fases iniciais da doença. Para isso, foi fundamental conhecer a sequência do genoma viral, uma vez que os cientistas precisam "pescar" essas células específicas em amostras de pacientes em meio a todas as outras células B presentes no sangue.

Mais especificamente, para que essa pesca possa acontecer, é necessário produzir uma "isca". Uma vez que o genoma do SARSCoV-2 foi disponibilizado no início de 2020, o MIL foi capaz de produzir in vitro a proteína espícula viral que reveste o vírus. Essa proteína foi então marcada com uma molécula fluorescente para ser utilizada em um experimento no qual misturamos essa isca com as células B dos pacientes com Covid-19. Após essa incubação, é esperado que as células $B$ capazes de reconhecer o vírus se liguem a essa proteína. Porém, não podemos esquecer, que apenas uma quantidade muito pequena dessas células será capaz de reconhecer o vírus. Terminada essa incubação, as células são, então, analisadas em um equipamento chamado citômetro de fluxo. De maneira simplificada, podemos dizer que essa máquina é capaz de analisar células individualmente e, com o auxílio do pesquisador, é capaz de selecionar as células $\mathrm{B}$ ligadas à isca fluorescente. Esse procedimento, nomeado single cell sorting, permite, portanto, a identificação e captura dessas células específicas, possibilitando a obtenção da informação genética contida nas células $B$ que respondem às células infectadas. A partir dessa informação genética, o próximo passo é a clonagem desse DNA e a utilização do mesmo para produção dos anticorpos in vitro. Uma vez produzidos, diversos experimentos foram realizados para verificar a sua capacidade em se ligar e neutralizar o vírus impedindo a infecção das células alvo ${ }^{3}$.

No caso específico da pesquisa desenvolvida no MIL, o laboratório teve acesso às proteínas virais já no início de março de 2020 e as primeiras células dos pacientes foram isoladas em abril de 2020. Essa rapidez no processo foi possível, principalmente, pela colaboração de cinco laboratórios distribuídos em diversas regiões dos EUA e também pela existência do conhecimento necessário

3 Mais informações detalhadas sobre todo esse processo podem ser encontradas em (Robbiani et al., 2020). 
As mediações no desenvolvimento de um tratamento para a Covid-19: pescando actantes Bruno Rossi Lorenzi • Tarcísio de Sá Cardoso • Julio Cesar Cetrulo Lorenzi

para cada passo desse tipo de pesquisa, que já tinha sido realizada para outros vírus como HIV e zika (ROBBIANI et al., 2017; SCHEID et al., 2009).

A partir desse conhecimento, diversos laboratórios no mundo começaram a estudar esse processo e tentar capturar essas células B específicas para o SARS-CoV-2, no intuito de produzir in vitro os anticorpos derivados das mesmas. No momento em que escrevemos este artigo, diversos ensaios clínicos estavam testando a possibilidade do uso desses anticorpos como primeira linha de tratamento em pacientes infectados com o SARS-CoV-2 (VAN RIEL; DE WIT, 2020). Entendemos que esse tratamento tem grande chance de funcionar, uma vez que esses anticorpos têm a capacidade de neutralizar o vírus causador da Covid-19.

\section{Latour, a noção de rede e as mediações}

Uma vez que a principal referência teórica deste trabalho para se discutir as redes de ação da ciência no combate ao SARS-CoV-2 é a obra de Bruno Latour, antes de entrar propriamente nas controvérsias envolvidas nas redes da ciência em ação, é importante fazer um apanhado geral sobre os fundamentos latourianos que utilizaremos para sustentar uma reflexão sociológica compromissada com o social-natural do contexto de pandemia, de modo que o leitor possa se situar com relação à base conceitual aqui adotada. Sabe-se, no entanto, que a obra de Bruno Latour é bastante ampla, não sendo nossa pretensão aqui apresentá-la em seus detalhes. Para dar conta do objetivo deste artigo, serão priorizados conceitos como rede, mediação e actante, tal como aparecem nas obras $A$ esperança de Pandora (LATOUR, 2001), Ciência em ação (LATOUR, 2000), Reagregando o social (RoS) (LATOUR, 2012), Jamais fomos modernos (IFM) (LATOUR, 1999) e Investigações sobre os modos de existência (IME) (LATOUR, 2019). Justamente porque tal recorte perpassa diferentes momentos da obra latouriana, tentaremos a partir de agora esclarecer: (1) como a noção de rede aparece de 
As mediações no desenvolvimento de um tratamento para a Covid-19: pescando actantes Bruno Rossi Lorenzi • Tarcísio de Sá Cardoso • Julio Cesar Cetrulo Lorenzi

uma forma mais "técnica" na fase mais recente do pensamento latouriano (a partir da obra IME); (2) como a noção de mediação aparece com mais desenvolvimento na fase anterior, de crítica ao "dualismo moderno"; e também como a teoria ator-rede (TAR), sistematizada em Reagregando o social (RoS) (2012), foi revisada por Latour em Investigações sobre os modos de existência (IME) (2019).

Em IME (LATOUR, 2019), publicado originalmente em 2012, o autor elabora uma reflexão mais propriamente filosófica sobre as investigações de caráter mais antropológico e sociológico anteriores na sua obra. Neste sentido, e especialmente do ponto de vista ontológico, ou talvez até mais do ponto de vista ontogenético, o pensamento latouriano manifesta um grande interesse pela pluralidade das formas através das quais algo pode vir a ser. Neste tipo de meta-reflexão de caráter categorial, Latour acaba revisando sua própria proposta teórica anterior, a teoria ator-rede (TAR). Apesar de não refutar a TAR, Latour a posiciona agora como um dos seus quinze modos de existência, aproximando-a ao que se entende por epistemologia e, talvez mais ainda, por metodologia, mas que na linguagem latouriana aparece como "metalinguagem da investigação". Já no primeiro capítulo de IME, Latour apresenta esta metalinguagem da investigação, que antes chamava de TAR, como o modo rede, com grafia [RES] (entre colchetes, mesmo) para designá-lo como parte integrante do vocabulário técnico adotado.

Ao caracterizar o modo [RES], Latour (2019, p. 39-46) explica que se trata da arte de explorar entidades necessárias à existência de outras entidades, já que redes são coletivos de relações, composições de elementos heterogêneos articulados de forma a produzir um sistema relacional dinâmico e instável, mas que, devido às ações de manutenção, aparenta ser estável. Por tratar todo coletivo como associação de heterogêneos, [RES] seria uma espécie de método de investigação similar ao de um antropólogo, isto é, um método interessado em entender uma cultura (próximo à etnometodologia), que adota uma postura conhecida como um ceticismo metódico (que propõe uma ida a campo a partir de um não saber) e de base empírica (já que propõe um descrever 
As mediações no desenvolvimento de um tratamento para a Covid-19: pescando actantes Bruno Rossi Lorenzi • Tarcísio de Sá Cardoso • Julio Cesar Cetrulo Lorenzi

dos elementos que agem no coletivo, a partir daquilo que a experiência apresenta como fenômeno), e que sugere uma espécie de achatamento do social em questão, destacando, a cada etapa de descrição, seu arranjo composicional. No entanto, partir da rede não significa empreender uma busca totalmente errática e desinteressada. O que se pretende é ressaltar os elementos que agem em um coletivo, visando captar a construção de sua episteme. Ao fazê-lo desse modo, o [RES] consegue "antropologizar" epistemes das nossas sociedades modernas, isto é, tratar ciência, direito, economia e religião como se fossem arranjos da mesma espécie, ou seja, trata a todas como redes de elementos distintos (heterogêneos), mas que se articulam de um modo específico para produzir determinados resultados socialmente relevantes.

Percebe-se que o que se propõe com a noção de "[RES]" é, antes de tudo, uma espécie de nivelamento metódico entre domínios ${ }^{4}$ diferentes. Diante de tal proposta, que poderia soar insultuosa, poderíamos perguntar: o que tal nivelamento, entre áreas claramente diferentes (direito, ciência, religião), consegue captar? A resposta latouriana, parece-nos, seria algo como: o que se consegue captar é o modo de ser das instituições modernas. Mas poderíamos continuar a indagação: que vantagem há nessa proposta de tratar a todas as instituições a partir do mesmo fundamento [RES]? É o próprio Latour que responde:

A noção de rede, especificando-a agora um pouco, designa uma série de associações revelada por meio de uma prova - a das surpresas da pesquisa etnográfica - que permite compreender por quais séries de descontinuidades convém passar para obter certa continuidade de ação. Esse princípio de livre-ASSOCIAÇÃO - ou, para ser mais preciso, esse princípio de IRREDUÇÃO -, que está no cerne da teoria ator-rede, demonstrou sua fecundidade ao permitir que muitos observadores tomassem em seus estudos tanta liberdade de movimento quanto seus informantes (LATOUR, 2019, p. 39-40 - grifos do autor).

\footnotetext{
4 Vale lembrar que "domínio" é uma palavra rejeitada por Latour, que não pretende partir de classes definidas a priori, mas pretende justamente se perguntar o que distingue cada área como tal, não a partir de definições abstratas, demarcações lógicas ou conceituais, mas a partir de seu fazer (donde se infere o caráter pragmático da proposta teórica latouriana, no qual nada vale por si, tudo vale pela sua ação na rede).
} 
As mediações no desenvolvimento de um tratamento para a Covid-19: pescando actantes Bruno Rossi Lorenzi • Tarcísio de Sá Cardoso • Julio Cesar Cetrulo Lorenzi

Diante da resposta de Latour (2019), percebe-se que a noção de rede diz respeito a uma espécie de princípio guia para a investigação do coletivo ou do "social" (associação de heterogêneos) em questão, sendo tal princípio baseado nas múltiplas relações entre continuidades e descontinuidades. Ao avaliar uma petição, juristas veem relações (de continuidade) entre partes distintas (e descontínuas) da legislação. Ao buscar uma vacina para um vírus, cientistas veem continuidades entre sua anatomia representada em uma imagem computacional, uma fórmula anotada em uma lousa e uma descrição textual expressa em um artigo científico. Conseguir ver boas continuidades entre elementos aparentemente descontínuos é o grande mérito de um bom jurista e de um bom cientista. E conseguir ver as redes descontínuas que, no entanto, são vistas pelo cientista/jurista como contínuas, é o objetivo de um antropólogo das instituições modernas. Desse modo, Latour vai dizer, finalmente: rede é o modo de ver pelo qual "se obtém uma continuidade por meio de descontinuidades" (2019, p. 46).

Segundo o autor de IME, é preciso perceber como diferentes modos de existência coexistem e se cruzam se quisermos entender como produzimos continuidades (ou seja, sentidos, sejam eles na forma de conhecimento, tecnologia, leis etc.), a partir das descontinuidades que permeiam o mundo. Em suas palavras:

[...] aprendemos nos capítulos anteriores que nossa investigação tinha a ver com a identificação de um tipo de TRAJETÓRIAS cuja continuidade aparente era de fato obtida por uma maneira peculiar de saltar sobre as descontinuidades, que são diferentes a cada ocasião. (LATOUR, 2019, p. 69-70 - grifo do autor)

De acordo com o autor, cada modo de existência possui a sua chave de leitura, ou preposição [PRE], assim como suas condições particulares de felicidade e infelicidade (que podemos interpretar como suas condições de sucesso). Latour (2019) aponta quinze modos distintos de existência, sem a intenção de esgotar as possibilidades. Neste artigo, iremos focar nossa atenção em dois modos particulares, no caso, o modo Reprodução [REP] e o modo 
As mediações no desenvolvimento de um tratamento para a Covid-19: pescando actantes Bruno Rossi Lorenzi • Tarcísio de Sá Cardoso • Julio Cesar Cetrulo Lorenzi

Referência [REF], devido ao fato de que o cerne da atividade científica - ou a produção de móveis imutáveis ${ }^{5}$ - especialmente em casos como o que analisamos, se daria justamente no cruzamento entre esses dois modos.

O modo Reprodução [REP] seria a forma pela qual as entidades físicas de qualquer espécie permanecem existindo. Assim como a vida, isso se daria fundamentalmente através da reprodução, seja ela no sentido de permanecer ou de se replicar (LATOUR, 2019). Sendo assim, um átomo de urânio-235, por exemplo, segue existindo enquanto tal até o momento em que decai. Mesmo após o seu decaimento, algo da parte original se mantém, ao mesmo tempo em que a mudança (no caso, o decaimento) faz parte de sua trajetória enquanto um ser no mundo. Da mesma forma, um vírus replica seu código genético através da infecção de outras células, reproduzindo-se ao mesmo tempo em que muta lentamente a cada replicação.

Já o modo Referência [REF] é a forma pela qual nós encontramos de conectar coisas diferentes por meio de suas semelhanças, categorizadas a partir do nosso entendimento do mundo. Esse modo encontra sua versão mais desenvolvida no que chamamos de ciências (naturais, sociais ou do direito), já que essas atividades seriam impraticáveis, ou não teriam nenhuma legitimidade, não fossem as longas cadeias de referência que criam, possibilitando o resgate da informação, a revisão por pares e o encadeamento lógico de modelos, conceitos e teorias científicas. Nas palavras do autor:

Vamos, portanto, denominar como [REP] a REPRODUÇÃO (insistindo, é claro, no prefixo "re", de reprodução), o modo de existência pelo qual uma entidade qualquer atravessa o hiato de sua repetição, definindo assim, de etapa em etapa, uma trajetória particular, em que o conjunto obedece a condições de felicidade particularmente exigentes: ser ou não ser mais!

\footnotetext{
5 Segundo Latour (2001, p. 350), toda inscrição científica (conceitos, definições, artigos, teorias, etc), são como móveis imutáveis, ou seja, permitem novas translações e circulações (por isso, móveis) ao mesmo tempo em que algumas relações e características são mantidas intactas (portanto, imutáveis). Quando essas partes são alinhadas produzem as Referências Circulantes (por meio das quais podemos traçar a trajetória dessas ideias e inscrições), tão características da ciência e do direito.
} 
As mediações no desenvolvimento de um tratamento para a Covid-19: pescando actantes Bruno Rossi Lorenzi • Tarcísio de Sá Cardoso • Julio Cesar Cetrulo Lorenzi

Sem surpresas, usaremos a notação [REF] (de REFERÊNCIA) para designar o estabelecimento das cadeias definidas pelo hiato entre as duas formas de natureza diferente e cuja condição de felicidade consiste na descoberta de uma constante que se mantém através desses abismos sucessivos, desenhando outra forma de trajetória que torna acessíveis os distantes, cobrindo o trajeto com o movimento em duplo sentido dos móveis imutáveis (LATOUR, 2019, p. 85).

Mas ao contrário do direito, que sobrevive perfeitamente encadeando apenas referências legais e morais, a ciência precisa das entidades físicas da Reprodução para construir seus experimentos, produtos e artefatos. É, portanto, a partir do cruzamento de [REP] e [REF] que é possível, por exemplo, desenvolver uma vacina ou um tratamento para a Covid-19. A forma como esse cruzamento se dá na prática ficará mais clara quando analisarmos o desenvolvimento de um tratamento para a Covid-19 pelo MIL na próxima seção.

Para Latour, as redes ou cruzamentos são associações de heterogêneos, cujas partes interferem-se mutuamente o tempo todo. Assim, captar a essência de uma rede é compreender o complexo de coconstrução em que se baseia, isto é, o que interessa no tratamento conceitual de um fragmento do social como rede é, antes de tudo, entender as ações dos seus atores, isto é, dos elementos que estão no meio dos seus processamentos, já que são eles que fazem emergir um produto desta ou daquela sociedade, desta ou daquela comunidade. Na maturidade do seu pensamento, Latour explica, finalmente, que mesmo para permanecer é preciso estar se reinventando constantemente:

A ESSÊNCIA de uma situação, por assim dizer, será - no caso de [RES] - a lista dos outros seres pelos quais é conveniente passar para que esta situação dure, se prolongue, se mantenha ou se estenda. Traçar uma rede é sempre reconstruir por uma PROVA (a investigação é uma prova, mas a inovação é outra, assim como a crise) os antecedentes e consequentes, ou, para dizer ainda 
As mediações no desenvolvimento de um tratamento para a Covid-19: pescando actantes Bruno Rossi Lorenzi • Tarcísio de Sá Cardoso • Julio Cesar Cetrulo Lorenzi

de outra forma, os precursores e os herdeiros, a integralidade de um ser. Ou, para falar mais filosoficamente, os outros pelos quais se deve passar para se tornar ou permanecer o mesmo (LATOUR, 2019, p. 46 - grifos do autor).

Para identificar o modo como uma rede se constitui, é preciso, no entanto, compreender a ação pela qual algo se transforma, se traduz em outro (tradução), observando, de todo modo a ação dos meios (mediação) pelos quais os heterogêneos se articulam para engendrar um coletivo complexo. Tradução e mediação são, neste sentido, os conceitos que subsidiam a própria vida das redes, quaisquer que sejam elas. Estes conceitos, amplamente utilizados nas obras de Latour, referem-se ao universo das ações nas redes de heterogêneos, ações estas que podem ser captadas se traçadas por descrições das alterações na configuração da rede enquanto um resultado estável, que quando maduro o suficiente será apresentado publicamente como acabado.

Em JFM (LATOUR, 1999), é apresentado o conceito de mediação como aquilo que não é passível de ser captado pelo dualismo moderno "Cultura X Natureza", justamente porque não se coloca nem no polo da cultura, nem no da natureza (entendidos como uma polaridade do par "C-N", colocados cada um em um dos extremos de uma linha horizontal), mas, antes em um outro eixo, que deve ser a ele acrescentado (o eixo vertical), que inclui as práticas da mediação. Nas palavras do autor: “à prática de purificação - linha horizontal -, convém acrescentar as práticas de mediação - linha vertical" (LATOUR, 1999, p. 43). Nesta linha de crítica ao moderno, o argumento latouriano daquele período acrescenta ainda que mesmo no auge da sua Constituição, expressa pelo projeto epistemológico da Crítica da razão pura kantiana, sempre houve uma modernidade oficiosa ocultada por trás da modernidade oficial.

É em sua face oficiosa, no entanto, que habitam e operam as mediações, e é apenas a partir delas que seria possível perceber aquilo que a filosofia, a sociologia e a ciência moderna nunca puderam perceber sobre si próprias. Isto significa, para Latour, que 
As mediações no desenvolvimento de um tratamento para a Covid-19: pescando actantes Bruno Rossi Lorenzi • Tarcísio de Sá Cardoso • Julio Cesar Cetrulo Lorenzi

independente da Constituição e do modo de estabelecer seu sistema de verdade (racional, social ou objetiva), o homem moderno, que se crê emancipado de todo fantasma do misticismo porque domina o mundo à sua volta com o uso da razão, jamais conseguiu perceber que a conquista sentida por seu projeto emancipador era uma conquista ilusória e dependente de seu próprio fechar de olhos para as práticas oficiosas da mediação. Desse modo, “[...] o preço a pagar por esta liberdade foi que os modernos permaneceram incapazes de pensar a si mesmos. Todo o trabalho de mediação escapa do quadro constitucional que o traça e o nega" (LATOUR, 1999, p. 45).

Se mediação é o mecanismo oficioso das ações em rede, em processo de estabilização, poderíamos perguntar: quem exerce ações no social? Classicamente, o ator social, por excelência, é o humano. No entanto, Latour $(1999,2000,2001)$ argumenta que a sociologia precisa alargar esta compreensão de modo a incluir atores não humanos, que agem ou atuam sobre o mundo ou em algum projeto (como a construção de tecnologias ou pesquisas científicas). Para o autor, portanto, atores não humanos também são atores na rede, ou seja, também modificam o curso de nossas ações, influenciam nossos arranjos e decisões, agem como mediadores. Isso fica evidente quando paramos para pensar o quanto as materialidades das tecnologias eletroeletrônicas, como informáti$\mathrm{ca}$, e seus desdobramentos na grande rede mundial (internet) estão incorporados à nossa vida. A maior parte de nossas conversas, ações e transações no mundo de hoje, exacerbadas pelo distanciamento social provocado pela pandemia, são mediadas por algum ator não humano, como computadores, smartphones, mediados por torres e cabos das empresas de telecomunicações, sem os quais nossas redes de Facebook, Instagram, WhatsApp e mesmo este artigo não existiriam. A atuação dos elementos técnicos nessas situações é absolutamente indispensável e esses arranjos são conformados mediante exigências tanto sociais quanto técnicas, ou melhor, sociotécnicas. É por conta da indistinção funcional en- 
As mediações no desenvolvimento de um tratamento para a Covid-19: pescando actantes Bruno Rossi Lorenzi • Tarcísio de Sá Cardoso • Julio Cesar Cetrulo Lorenzi

tre humanos que agem e não humanos que também agem, que Latour prefere não falar de "ator social", mas de actante ${ }^{6}$.

\section{A busca da ciência revisitada a partir dos conceitos latourianos}

Após ter apresentado, em linhas gerais, a Covid-19 e o caso específico da pesquisa para o tratamento desta doença, e após tomarmos conhecimento do ferramental teórico de Bruno Latour, estamos em condições de aplicar os conceitos aprendidos para esclarecer aspectos da busca das ações da ciência. Assim, tentamos a seguir interpretar o tratamento em desenvolvimento pelo MIL, através dos conceitos latourianos, no intuito de relacionar a prática científica exposta anteriormente à leitura teórica que nos parece pertinente para ajudar a revelar qualidades sociais das atividades investigativas da ciência.

Assim, tendo em mente o desafio da ciência que se coloca em ação para compreender e agir em contraposição a outra ação (a ação do vírus), e tendo em mente também as diversas camadas de ações sociais e políticas que se acrescentam no já conturbado cenário da pandemia, propomo-nos aqui a incluir a perspectiva teórica latouriana, que nos parece relevante para lidar justamente com as camadas de complexidade que este fenômeno tão singular apresenta para a vida em sociedade em praticamente todas as regiões do planeta. Especialista precisamente nos espaços de interseção entre os territórios relativos à ação da ciência, Latour entende que as ações da ciência estão sempre além do universo dos cientistas, já que agem na esfera pública e interferem no social. Assim, as ações da ciência no social e a própria ciência em ação compreendem o que costumamos entender como as esferas da filosofia, sociologia e, mesmo, antropologia da ciência. Tais esferas constituem em conjunto um espaço dentro do qual é possível entender

6 Actante é mais um conceito técnico no pensamento latouriano. Inspirado na semiótica de Algirdas Greimas, Latour usa o termo "actante" para se referir a qualquer coisa que tenha poder de agência, isto é, que possa gerar ações na rede em questão. 
As mediações no desenvolvimento de um tratamento para a Covid-19: pescando actantes Bruno Rossi Lorenzi • Tarcísio de Sá Cardoso • Julio Cesar Cetrulo Lorenzi

a busca da ciência como uma busca que é afetada, condicionada e permeada por ações políticas, ações que interferem não só nas ações possíveis aos cientistas, mas também, nas ações possíveis a todos os indivíduos inseridos no social. Desde os profissionais de saúde, que aplicam os conhecimentos na cura de pessoas, até os cidadãos que sequer chegaram a ter o atendimento adequado por conta da ineficiência na aplicação de políticas públicas adequadas, ou mesmo os familiares destes cidadãos que sofrem, indiretamente, as consequências dessas ações ou da falta de ações tomadas nas redes que compõem a vida em sociedade.

Quando a discussão chega nesse nível tão distante do cientista que está no laboratório, pode parecer que já não está mais se falando da mesma coisa. No entanto, o convite de Latour é para que, ao invés de pensarmos que isto já é outro departamento, outro domínio, pensemos, ao contrário, nas redes que conectam diferentes domínios, nas redes de ações que compõem um social, nas quais estão incluídas a ciência, as políticas públicas, os atores humanos envolvidos no combate à pandemia, os atores não humanos, como os protocolos das instituições (que seriam elas próprias espaços de engendramentos de ações), os equipamentos usados pelos atores (eles próprios atores que permitem ações), e o próprio vírus, que passa a ser entendido como mais um dos atores (e um ator extremamente fundamental) neste complexo jogo do social.

A todo tempo, atores não humanos oferecem resistência aos nossos modelos, teorias, experimentos e intenções, que interferem diretamente no resultado final, já que possuem o que podemos chamar de comportamento que lhes é próprio. De certa forma, há uma luta que os cientistas travam contra o avanço da pandemia, tentando compreender o vírus para poder controlá-lo, ao mesmo tempo em que o vírus se propaga em velocidades assustadoras e coloca em xeque as próprias vidas humanas e os sistemas de saúde das sociedades. Do ponto de vista latouriano, portanto, todos os elementos que agem são importantes, e todos eles resistem a outras ações, sendo, não só resistentes, mas também existentes, 
As mediações no desenvolvimento de um tratamento para a Covid-19: pescando actantes Bruno Rossi Lorenzi • Tarcísio de Sá Cardoso • Julio Cesar Cetrulo Lorenzi

no sentido daquilo que é real, independente de ser também social (não é o objetivo deste artigo entrar no debate mais epistemológico, mas vale lembrar que em Latour a própria dicotomia entre "realidade" e "sociedade" se desfaz).

Assim, tanto do ponto de vista das políticas públicas de saúde, quanto do ponto de vista das ciências da saúde, a realidade se força sobre nós, impondo cuidados redobrados com a saúde, intervindo na vida social, afetando a rotina de populações inteiras e em todos os lugares do planeta. O que canaliza as nossas ações para direções antes impensáveis, criando novas práticas culturais e políticas emergenciais de afastamento social, afetando dinâmicas mercadológicas de modo a trazer consequências para as economias locais e globais, mobilizando ações e investimentos em pesquisas, a partir de uma nova prioridade, e mesmo trazendo dores, marcas, angústias e traumas psicológicos novos, que podem levar gerações e gerações para serem assimilados e superados. Esse tipo de reflexão que coloca em uma mesma rede fenômenos sociais e biológicos pode (e do ponto de vista latouriano, deve) nos fazer engajar em uma investigação sociológica entendida em sentido amplo, isto é, tomando "social" como um tipo de fenômeno composto, simultaneamente, por humanos e não humanos. Seguindo esta linha de raciocínio, tomamos, neste texto, o caso da pandemia do novo coronavírus a partir da perspectiva das mediações em redes de híbridos, de tal modo que o social e o natural sejam parte de uma mesma tessitura de agenciamentos interconectados.

Para construir o conhecimento científico, cientistas, engenheiros e gestores precisam mobilizar uma série actantes, como microscópios, tubos de ensaio, moléculas, micro-organismos, vírus, códigos genéticos, reações químicas, proteínas, anticorpos etc. Esses atores não humanos são absolutamente necessários para construir, por exemplo, uma vacina ou tratamento contra a Covid-19. No entanto, como Latour $(1994,2000,2001)$ demonstra, a partir de casos famosos (como o fermento de Pasteur, a bomba atômica e muitos outros ao longo de sua trajetória), esses actantes não se dobram simples- 
As mediações no desenvolvimento de um tratamento para a Covid-19: pescando actantes Bruno Rossi Lorenzi • Tarcísio de Sá Cardoso • Julio Cesar Cetrulo Lorenzi

mente à nossa vontade, pelo contrário, o tempo todo, especialmente nas fases iniciais de pesquisa, apresentam uma indeterminação em seu comportamento, agindo de modo independente do que desejam os cientistas. É preciso, portanto, traduzi-los, ou seja, mapear sua constituição e comportamento, prever suas reações, de forma a tornar úteis determinadas características pesquisadas pelos cientistas, de modo a incorporá-los à rede.

Segundo Latour (2000), tradução (ou translação) possui dois sentidos: o primeiro é linguístico, no sentido de traduzir (modificar) interesses e representações, podendo fazer com que objetivos, interesses e características distintas de dois ou mais atores ganhem um novo sentido, mais adequado. O segundo, consequente deste, é geométrico, ou seja, de trazer aliados para a rede de forma a contribuir para a construção de um fato ou uma tecnologia. Como Law afirma, "tradução é um verbo que implica transformação e a possibilidade de equivalência, a possibilidade que uma coisa (por exemplo, um ator) possa representar outra (por exemplo, uma rede)" (LAW, 2003, p. 5-6).

Se tanto humanos como não humanos são capazes de agência e mediação, é porque independentemente da sua natureza física, biológica ou sociológica, são capazes de influenciar o curso da ação e associar outros actantes. Esses processos de tradução ficam claros na pesquisa do MIL, aqui apresentada, quando os cientistas buscam identificar e capturar as células B que produzem os anticorpos que combatem o coronavírus no sangue dos pacientes que respondem bem à doença em sua fase inicial. Para isso, foi necessário produzir in vitro - a partir do genoma já mapeado do vírus - a proteína que o reveste, para que servisse de antígeno (ou "isca" nesse caso) para as células B específicas que combatem o vírus serem "pescadas", como descrito pelo pesquisador do MIL envolvido na pesquisa (coautor neste artigo) em seção anterior. Aqui podemos observar uma cadeia de mobilização (ou traduções), na qual um actante não humano, já mobilizado e integrado à rede, traduz outros actantes não humanos. No caso, o genoma que traduz a proteína, que serve de isca para se capturar e mobilizar especifi- 
As mediações no desenvolvimento de um tratamento para a Covid-19: pescando actantes Bruno Rossi Lorenzi • Tarcísio de Sá Cardoso • Julio Cesar Cetrulo Lorenzi

camente as células $B$, que produzem os anticorpos que combatem o vírus, para posterior produção in vitro dessas mesmas células e dos anticorpos sintetizados por elas.

\section{Mediações ou cadeia de traduções utilizada na presente análise}

Genoma do coronavírus $\rightarrow$ Pesquisadores do MIL $\rightarrow$ sintetização do revestimento proteico do vírus (antígeno, "isca") $\rightarrow$ "pescagem" das células B específicas $\rightarrow$ produção in vitro dos anticorpos.

Essa série de traduções também pode ser tomada como exemplo de continuidades que os cientistas são capazes de criar a partir das descontinuidades, típica do cruzamento [REP x REF] presente em toda atividade científica (LATOUR, 2019, p. 85-87). Ao pescarem as células $B$ específicas graças à isca produzida a partir do código do vírus, os pesquisadores do MIL foram capazes de produzir in vitro os anticorpos necessários ao tratamento, o que conecta de certa forma o vírus à cura. Aquilo que eram descontinuidades como o vírus que buscava simplesmente se reproduzir [REP] e o tratamento ainda não alcançado - foi convertido em continuidade (cf. Latour, 2019, p. 43-44) através dessa série de traduções, justamente na direção desejada pelos pesquisadores do MIL (que podemos chamar de condição de felicidade nesse caso), graças a esse cruzamento. Não fosse o mapeamento do código do vírus (um claro exemplo de [REF]), e o encadeamento de traduções que possibilitou capturar as células necessárias por meio da isca, não seria possível fazer as células B que produzem os anticorpos (ou seja, [REP]) atuarem no sentido desejado da pesquisa. Aqui também fica evidente a capacidade de atuação e associação de um actante não humano sobre outros (inclusive sobre o humano), já que seria impossível capturar as células B e fazê-las produzir os anticorpos necessários sem as proteínas virais marcadas com fluorescência que servem de "isca". A análise a partir de Latour poderia, de maneira ainda mais radical, destacar a agência dos não humanos no sentido inverso, de modo que se pudesse falar também que as células B, por suas propriedades, também “pescam" humanos que 
As mediações no desenvolvimento de um tratamento para a Covid-19: pescando actantes Bruno Rossi Lorenzi • Tarcísio de Sá Cardoso • Julio Cesar Cetrulo Lorenzi

no laboratório se interessam por responder a questões sobre o vírus, a vacina e os tratamentos.

Em casos da ciência em ação como o que estamos estudando neste artigo, os actantes mobilizados podem ser considerados "aliados", ou seja, atores (já que claramente atuam de forma decisiva para o funcionamento adequado da rede) incorporados à rede através de algum processo de tradução a promover uma parte importante da solução científica: o fechamento da caixa-preta (LATOUR, 2000). No caso do tratamento aqui apresentado, os pesquisadores do MIL transformaram as células B e seus anticorpos em mais um aliado nessa rede (que possui outros actantes fundamentais como o código genético do vírus, conhecimento de suas proteínas, dados sobre a infecção, mutações etc). Ao serem assim mobilizados e incorporados à rede, tornam-se um mecanismo essencial na obtenção desse tratamento ou caixa-preta em fechamento.

Da mesma forma, os seres humanos também são mobilizados e representados por outros atores o tempo todo. $\mathrm{O}$ exemplo mais óbvio é a democracia representativa. Entretanto, como Latour demonstra $(2000,2001)$, a maior parte do tempo nossas ações e decisões são construídas coletivamente, somos levados a crer e agir por uma infinidade de outros atores que nos ajudam a pensar o mundo e a nós mesmos. Isso é ainda mais evidente quando consideramos movimentos sociais ou projetos científico-tecnológicos, nos quais uma grande coletividade interfere nas ações e decisões do grupo, e são, geralmente, representados por um líder ou porta-voz. Portanto, não somos tão livres como às vezes imaginamos. Agimos na mesma medida em que somos levados a agir.

Em um projeto, cujo caráter tecnológico ou científico se sobressai, cientistas e engenheiros tanto direcionam coletivamente não humanos, no sentido que desejam (com variado grau de sucesso), quanto são por eles limitados e direcionados (o que chamamos de resistência). A via de mão-dupla é bem evidente no caso do coronavírus, pois, ao mesmo tempo em que os cientistas fazem experimentos e desenvolvem vacinas e tratamentos, 0 
As mediações no desenvolvimento de um tratamento para a Covid-19: pescando actantes Bruno Rossi Lorenzi • Tarcísio de Sá Cardoso • Julio Cesar Cetrulo Lorenzi

vírus também modifica o nosso comportamento, influenciando o desenvolvimento de tratamentos, políticas econômicas, de saúde, de distanciamento social etc. Políticas de compensação econômica, quarentena, construção de hospitais de campanha, cientistas, governos e o SARS-CoV-2 estão todos conectados e interferindo-se mutuamente.

A partir dessa exposição, fica mais claro entender por que Latour (1999) insiste em sua filosofia de que é falsa a cisão moderna entre humanos e não humanos. Nem humanos, nem não humanos agem sozinhos, já que a todo tempo pessoas estão ligadas a outras pessoas e a seus artefatos tecnológicos em praticamente tudo o que fazem. Como o autor demonstra em várias obras (LATOUR, 1999, 2000; 2001), todos os actantes da ciência no fundo são híbridos - arranjos sociotécnicos construídos por nós humanos e não humanos. É necessário, portanto, abandonarmos velhas distinções absolutas - como sociedade e natureza, humanos e não humano. Melhor ainda seria chamar esses actantes de quase-objetos, já que a noção de híbrido exige a pressuposição de que sociedade e natureza existem de forma independente.

Em contextos como o da pandemia, a sociedade como um todo espera respostas de cientistas e de agentes públicos, que se empenham na busca por conhecer e controlar o contágio da população pelo vírus. Para tal, precisam conseguir testar, experimentar, investigar o vírus, entendê-lo, como se pudessem dialogar com ele ou, em linguagem latouriana, estabelecer uma espécie de negociação com ele. Essa negociação poderia, no entanto, ser traduzida teoricamente pela ideia de mediação, isto é, a ação daquilo que está no meio do caminho, daquilo que ainda não é, de um quase-objeto ou de um quase-sujeito em um longo processo em rede, envolvendo milhares de actantes que se modificam mutuamente. O conceito de mediação é, portanto, fundamental para entendermos a importância da atuação, mobilização e heterogeneidade dos elementos dessa rede, fundamentais a uma análise que busca entender os processos científicos antigos ou atuais de forma sociotécnica. 
As mediações no desenvolvimento de um tratamento para a Covid-19: pescando actantes Bruno Rossi Lorenzi • Tarcísio de Sá Cardoso • Julio Cesar Cetrulo Lorenzi

\section{Considerações finais}

Neste trabalho, buscamos apresentar em linhas gerais as características da Covid-19, a busca da ciência para contribuir com soluções para a crise sanitária, por meio do controle do comportamento do coronavírus, de modo a "domesticá-lo" e desenvolver um tratamento para a doença. Em seguida, a partir de uma análise latouriana (centrada nas noções de actante, rede e mediação), esclarecemos aspectos das ações em rede em busca de objetivos, que são, no fim das contas, sociais.

Pudemos perceber, com Latour, que a ciência em ação é uma rede que, como modo [RES], além de ser um enorme agenciamento sociotécnico composto por profissionais (pesquisadores, orientadores, técnicos, estagiários, gestores etc.), instituições (institutos de pesquisa, universidades, investidores, agências de fomento etc.), equipamentos (tubos de ensaio, microscópio, lousas, citômetro de fluxo etc.), trata-se de uma rede de redes; já que a ciência, ela mesma, entendida como instituição, se relaciona com outras instituições (a indústria de fármacos, os atores da economia, os cursos de certificação e capacitação etc.). Entretanto, mais importante ainda é perceber as ações que geram outras ações nessa rede, de modo que seja possível visualizar o que está em jogo, quem está vencendo e o que pode acontecer em seguida. Interessado nesse tipo de articulação de conhecimentos sobre o social hiperconectado, a obra de Latour, como vimos, nos permite atentar para o que ocorre no [RES] da instituição científica, isto é, para os cruzamentos e as continuidades notáveis, mesmo quando o que se tem são elementos aparentemente descontínuos. É porque a ciência tem um modo característico de conectar fenômenos que ela constrói o conhecimento, e é assim que ela oferece o que tem de melhor, uma ação transformadora da realidade social. Como, então, a ciência age na vida das pessoas, no mundo concreto? Que respostas ela dá e que papel ela cumpre?

Uma pergunta que move os esforços da ciência em busca de tratamentos para a Covid-19 é: "como controlar o vírus?". Essa 
As mediações no desenvolvimento de um tratamento para a Covid-19: pescando actantes Bruno Rossi Lorenzi • Tarcísio de Sá Cardoso • Julio Cesar Cetrulo Lorenzi

pergunta pode ser traduzida em outra: "como impedir o vírus de se multiplicar?". No caso da resposta científica para essa questão, uma das formas de se controlar o vírus é, como vimos, através da produção de anticorpos que neutralizem a infecção viral (produção que, como vimos também, pode ser ativa, no caso da vacina, ou passiva, no caso dos tratamentos). No vocabulário latouriano, trata-se de uma ação (da ciência, entendida como rede sociotécnica) que visa que outra ação (do anticorpo) possa combater uma ação específica, considerada nociva (a proliferação do vírus).

Percebe-se que a rede que interessa a Latour quando investiga a ciência é a rede de ações, mais do que os próprios atores, que não passam de uma estabilização temporária de cruzamentos e arranjos na forma de [RES] que tendem a se modificar com o tempo. No entanto, para que essa rede de ações possa ser rastreada, é necessário que o analista perceba as ações que estão no meio do caminho, misturadas a outros atores-rede e traduções. Isso se torna mais facilmente visível em casos de controvérsias ou de inovações, como no caso apresentado. A partir da descrição e análise desse caso, pudemos notar que foi preciso mobilizar um actante "aliado" (células B específicas) para que ele consiga agir sobre o actante "inimigo" (o vírus), de modo a neutralizá-lo. Mas, para isso, foi preciso mobilizar "outro actante aliado", a cápsula proteica marcada com fluorescência que serve de isca, sintetizada a partir do genoma do vírus.

No presente texto, usamos a metáfora da pesca para nos referirmos a esta ação dos cientistas, como se eles estivessem tentando "pescar" as células B (metáfora que, como vimos no pensamento latouriano, poderia ser invertida para propor que cientistas fossem eles próprios fisgados por células B). Usamos ainda outra metáfora, a da "isca", para nos referirmos ao sociotécnico criado para tentar pescar as células desejadas. A analogia utilizada na ideia de "usar uma isca para pescar as células B" cumpre com uma dupla função: ilustrar a ação dos cientistas em suas buscas investigativas; e evidenciar o mecanismo sociotécnico de coconstrução envolvido na ciência em ação. 
As mediações no desenvolvimento de um tratamento para a Covid-19: pescando actantes Bruno Rossi Lorenzi • Tarcísio de Sá Cardoso • Julio Cesar Cetrulo Lorenzi

Pudemos perceber, finalmente, a partir desta análise latouriana da atividade científica de investigação sobre o coronavírus, que o objetivo dos cientistas interessados em estudar a resposta imune na doença é contribuir para o desafio mais amplo que suas pesquisas: servir ao projeto sanitário de controlar o avanço da Covid-19. Contudo, a ciência só pode contribuir, de fato, para este objetivo mais amplo se fornecer o seu tipo de resposta a partir de uma série de ações em rede. Ações estas que, como vimos, exigem uma série de protocolos, artifícios, recrutamentos e ajudas, que vão desde "pedir dinheiro na porta do vizinho" (institutos e agências de fomento) até "pescar com iscas próprias" (identificando células capazes de se ligar à proteína espícula do vírus), e que incluem uma reconexão, no próprio sociotécnico da ciência, dos polos "natureza" e "cultura" que a modernidade oficial tentou separar. Esse tipo de ação contribui muito para os objetivos referentes aos tratamentos. Como vimos no caso da pesquisa de terapia passiva desenvolvida do Laboratório de Imunologia Molecular, a ação, por exemplo, de capturar células B específicas para combater SARS-CoV-2, tornou possível a mediação de produzir in vitro os anticorpos derivados de tais células. Para a presente análise, todas as ações que se somam na rede de um coletivo importam para que ele possa permanecer, sem, no entanto, permanecer o mesmo. Desse modo, as ações da ciência são cheias de "não saber", de "erraticidade", de "negociação", de "recrutamento", "cruzamentos" e são também cheias de "descontinuidades contínuas" (LATOUR, 2019, p. 43-44) pelas quais os "móveis imutáveis" (ibid., p. 73), como as sociedades em tempos de pandemia e pós-pandemia, buscam permanecer sem permanecerem as mesmas.

Ao refletir sobre o que está em jogo no conflito sobre o coletivo no pós-pandemia, inclusive por meio de analogias entre a questão do vírus e a questão ambiental, Latour propõe que tratemos a complexidade do social a partir do prisma da rede sociotécnica e de seus agenciamentos. De modo que o distanciamento social, as descobertas de tratamentos para a Covid-19, a busca por vacina, as disputas de narrativas por meio das mídias e as ações de políti- 
As mediações no desenvolvimento de um tratamento para a Covid-19: pescando actantes Bruno Rossi Lorenzi • Tarcísio de Sá Cardoso • Julio Cesar Cetrulo Lorenzi

cas públicas nas diversas partes do planeta se conectam de forma a evidenciar o enviesamento infundado dos adeptos da marcha irrefreável da narrativa ocidental modernizante. Para Latour, ao contrário, "[...] estamos vendo que a ordem mundial, que nos diziam ser impossível de mudar, tem uma plasticidade espantosa" (LATOUR, 2020a). Já que o futuro continua em aberto, cabe-nos refletir que coletivo queremos construir daqui para frente.

\section{Referências}

ANDERSEN, Kristian G, et al. The proximal origin of SARS-CoV-2. Nat Med 26, p. 450-452, 2020.

BONI, Maciej F, et al. Evolutionary origins of the SARS-CoV-2 sarbecovirus lineage responsible for the Covid-19 pandemic. Nature microbiology, 28 Jul. 2020.

CUI, Jie.; LI, Fang.; SHI, Zheng.-Li. Origin and evolution of pathogenic coronaviruses. Nature reviews. Microbiology, v. 17, n. 3, p. 181-192, Mar. 2019.

KARAGIANNIDIS, Christian et al. Case characteristics, resource use, and outcomes of 10021 patients with Covid-19 admitted to 920 German hospitals: an observational study. The Lancet. Respiratory medicine, 28 Jul. 2020.

KORBER, Bette, et al. Tracking Changes in SARS-CoV-2 Spike: Evidence that D614G Increases Infectivity of the Covid-19 Virus. Cell, v. 182, n. 4, p. 812- 827.e19, 20 Aug. 2020.

LATOUR, Bruno. Jamais fomos modernos. São Paulo: Editora 34, 1999.

LATOUR, Bruno. Ciência em ação: como seguir cientistas e engenheiros sociedade afora. São Paulo: Unesp, 2000.

LATOUR, Bruno. A esperança de Pandora: ensaios sobre a realidade dos estudos científicos. Bauru: Edusc, 2001. 
LATOUR, Bruno. Reagregando o social: uma introdução à Teoria do Ator-Rede. Salvador: Edufba, 2012.

LATOUR, Bruno. Investigação sobre os modos de existência: uma antropologia dos Modernos. Petrópolis: Vozes, 2019.

LATOUR, Bruno. Imaginando gestos que barrem o retorno ao consumismo e à produção insustentável pré-pandemia. 3 Abr. 2020. Climainfo. Disponível em: https://climainfo.org. br/2020/04/02/barrar-producao-insustentavel-e-onsumismo. Acesso em: 02 fev. 2021.

LATOUR, Bruno. Não existe sistema capaz de resistir à viralidade da ação política (entrevista). El Pais, 24 Jul. 2020. Disponível em: https://brasil.elpais.com/cultura/2020-07-24/bruno-latour-nao-existe-sistema-capaz-de-resistir-a-viralidade-da-acao-politica.html. Acesso em: 02/02/2021.

LEDFORD, Heidi. Antibody therapies could be a bridge to a coronavirus vaccine - but will the world benefit? Nature, v. 584, n. 7821, p. 333-334, Aug. 2020.

LIU, Lihong, et al. Potent neutralizing antibodies against multiple epitopes on SARS-CoV-2 spike. Nature, v. 584, n. 7821, p. 450456, Aug. 2020.

LU, Roujian, et al. Genomic characterisation and epidemiology of 2019 novel coronavirus: implications for virus origins and receptor binding. The Lancet, v. 395, n. 10224, p. 565-574, 22 Feb. 2020.

MALLAPATY, Smriti. Investigation into covid origin begins but faces challenges. Nature, v. 587, p. 341, Nov. 2020.

MULLARD, Asher. How COVID vaccines are being divided up around the world. Nature. Disponível em: https://doi. org/10.1038/d41586-020-03370-6. Acesso em: 02 fev. 2021.

NKENGASONG, John China's response to a novel coronavirus stands in stark contrast to the 2002 SARS outbreak response. Nature medicine, v. 26, n. 3, p. 441, Mar. 2020. 
As mediações no desenvolvimento de um tratamento para a Covid-19: pescando actantes Bruno Rossi Lorenzi • Tarcísio de Sá Cardoso • Julio Cesar Cetrulo Lorenzi

RASMUSSEM, Angela L. On the origins of SARS-CoV-2. Nat Med 27, 9 (2021).

ROBBIANI, Davide F., et al. Recurrent Potent Human Neutralizing Antibodies to Zika Virus in Brazil and Mexico. Cell, v. 169, n. 4, p. 597-609.e11, 4 May 2017.

ROBBIANI, Davide F., et al. Convergent antibody responses to SARS-CoV-2 in convalescent individuals. Nature, v. 584, n. 7821, p. 437-442, Aug. 2020.

SCHEID, Johannes F., et al. Broad diversity of neutralizing antibodies isolated from memory B cells in HIV-infected individuals. Nature, v. 458, n. 7238, p. 636-640, 2 Apr. 2009.

VAN RIEL, Debby:; DE WIT, Emmie. Next-generation vaccine platforms for Covid-19. Nature materials, v. 19, n. 8, p. 810-812, Aug. 2020.

ZHOU, Peng, et al. A pneumonia outbreak associated with a new coronavirus of probable bat origin. Nature, v. 579, n. 7798, p. 270-273, Mar. 2020.

ZOST, Seth J., et al. Potently neutralizing and protective human antibodies against SARS-CoV-2. Nature, v. 584, n. 7821, p. 443-449, Aug. 2020. 